\title{
Recent advances in managing and understanding menstrual disorders
} Luis Bahamondes ${ }^{1 *}$ and Moazzam Ali $^{2}$

Addresses: ${ }^{1}$ Human Reproduction Unit, Department of Obstetrics and Gynaecology, Faculty of Medicine, University of Campinas, Caixa Postal 6181; 13084-971, Campinas, Brazil; ${ }^{2}$ Reproductive Health and Research, World Health Organization, Avenue Appia CH-1211 Geneva 27, Switzerland

* Corresponding author: Luis Bahamondes (bahamond@caism.unicamp.br)

Fl000Prime Reports 2015, 7:33 (doi:10.12703/P7-33)

All Fl000Prime Reports articles are distributed under the terms of the Creative Commons Attribution-Non Commercial License (http://creativecommons.org/licenses/by-nc/3.0/legalcode), which permits non-commercial use, distribution, and reproduction in any medium, provided the original work is properly cited.

The electronic version of this article is the complete one and can be found at: http://f1000.com/prime/reports/m/7/33

\begin{abstract}
Menstrual disorders are a major reason for gynaecological consultations worldwide and, unfortunately there are many different definitions and classifications of this condition. Clear definitions and terminology are necessary for scientific literature, particularly for clinicians, and for clinical trials comparing two treatments. The International Federation of Gynaecology and Obstetrics (FIGO) Menstrual Disorders Working Group has proposed abandoning the use of one common term, dysfunctional uterine bleeding (DUB), while continuing to use the terms abnormal uterine bleeding (AUB) and heavy menstrual bleeding (HMB). Furthermore, the group issued the PALM-COEIN classification system for menstrual disorders, which has quickly been adopted around the world. The PALM-COEIN system allows clinicians and researchers to identify and classify women with both AUB and HMB in a systematic manner, provides reliable information for research purposes and for epidemiological and prevalence studies in different settings, and supports accurate diagnoses and treatment. Additionally, this classification system is useful for selecting treatments appropriate for different stages of women's reproductive years and for different patterns of menstrual bleeding. Among the proposed treatments are the use of combined oral contraceptives, the levonorgestrel-releasing intrauterine system, tranexamic acid, mefenamic acid, and other nonsteroidal anti-inflammatory drugs (NSAIDs).
\end{abstract}

\section{Introduction}

Menstrual disorders are a major reason for gynaecological consultations around the world and, unfortunately, many different definitions and classifications are used for this condition. Among the most commonly used terms, DUB is defined in the UK as the regular, cyclic, predictable onset of uterine bleeding after the exclusion of other pathologies, but in the US as irregular uterine bleeding associated with ovulatory disorders [1]. Clear definitions and terminology are important for scientific literature, particularly for clinical practice, and for clinical trials that compare two treatments and whose inclusion criteria is a main menstrual disorder [2]. In addition, various terms used to describe HMB include menometrorrhagia, metrorrhagia and polymenorrhoea. In many cases, such differing terms make it extremely difficult to interpret the patient's pathology or bleeding condition. As at intake a healthcare professional records the patient's history and typically recorded volume (heavy, normal or light), regularity (irregular, regular or absent), frequency (frequent, normal or infrequent), and duration (prolonged, normal or shortened) of menstrual episodes, each term could be interpreted differently across the globe.

HMB is a principal menstrual disorder, which has a negative impact on women's quality of life, causes the loss of working days, and incurs direct, considerable costs on healthcare systems worldwide [3]. HMB is defined as a blood loss of $>80 \mathrm{ml}$ per cycle (Table 1) [4]. However, only research centres can accurately measure menstrual blood loss due to the complexity of the techniques [5]. 
Table I. Normal limits for menstrual patterns in women in the mid-reproductive years

\begin{tabular}{lll}
\hline Variables & Descriptive terms & Normal limits (5th-95th percentiles) \\
\hline Frequency of menses (days) & Frequent & $<24$ \\
& Normal & $24-38$ \\
Infrequent & $>38$ \\
Regularity of menses (cycle to cycle variation & Absent & - \\
over I months in days) & Regular & Variation \pm 2 to 20 \\
& Irregular & Variation greater than 20 \\
Duration of flow (days) & Prolonged & $>8.0$ \\
& Normal & $4.5-8.0$ \\
Volume of monthly blood loss $(\mathrm{ml})$ & Shortened & $<4.5$ \\
& Heavy & $>80$ \\
& Normal & $5-80$ \\
\hline
\end{tabular}

Adapted with permission from [8].

Therefore, for clinical purposes, HMB is defined as "excessive menstrual blood loss which interferes with the woman's physical, emotional, social and material quality of life, and which can occur alone, or in combination with other symptoms" [6].

\section{Causes of menstrual disorders}

We need to establish the necessary parameters to achieve an accurate diagnosis and treatment for women with AUB. This is especially important with women who present with $\mathrm{HMB}$, which can be defined differently in developed countries with access to the latest technologies, compared with low-resource settings characterised by economic and technological constraints [7]. It is important to note that an accurate diagnosis improves treatment, the goal of which is to improve the patient's symptoms and quality of life.

\section{Classification of menstrual disorders}

In 2005, the FIGO Menstrual Disorders Working Group proposed abandoning some terms for menstrual disturbances, which are controversial, confusing and poorly defined, although they remain common in many scientific publications [8]. Many of these terms which are no longer recommended include English terms with Latin and Greek roots, and agreement was reached to abandon their usage. These terms include: menorrhagia, metrorrhagia, essential menorrhagia, idiopathic menorrhagia, primary menorrhagia, functional menorrhagia, ovulatory or anovulatory menorrhagia, hypermenorrhoea, hypomenorrhoea, menometrorrhagia, polymenorrhoea, polymenorrhagia, epimenorrhoea, epimenorrhagia, metropathica hemorrhagica, uterine hemorrhage and dysfunctional and functional uterine bleeding. It was recommended that the old term "dysfunctional uterine bleeding" be divided into three classifications: (1) disorders of endometrial origin (disturbances of the molecular mechanisms responsible for regulation of the volume of blood lost at menstruation); (2) disorders of the hypothalamic-pituitary-ovarian axis; and (3) disorders of haemostasis, or nonstructural causes of AUB [9-11].

The most recent version of the International Statistical Classification of Diseases and Health Related Problems (ICD), the ICD-10 (2010) [12], still uses such terms as metrorrhagia, menometrorrhagia and polymenorrhoea (N91, N92, N93) for HMB symptoms not related to a pathological process. The ICD-10 does not state if these terms refer to a pathology, symptom or diagnosis made by a healthcare professional. The most important problem created by this ambiguity is the lack of reliable information about prevalence for health authorities and policy makers. From a research perspective, as the definition for menstrual irregularity varies in different settings as stated above, it becomes difficult to make comparisons among clinical studies.

Furthermore, the FIGO Menstrual Disorders Working Group introduced a new classification called the PALMCOEIN system of AUB [9]. The consensus established that AUB is an appropriate term because it includes several clinical symptoms (although the use of the word "menstrual" is not correct), but at the same time implies that it should exclude bleeding coming from the cervix or the lower genital tract. It is also proposed that acute AUB could be classified as "an episode of bleeding in a woman of reproductive age, who is not pregnant, that is of sufficient quantity to require immediate intervention to prevent further blood loss". Additionally, chronic AUB is "bleeding from the uterine corpus that is abnormal in duration, volume, and/or frequency and has been present for the majority of the last 6 months" [13]. Table 1 shows a classification of normal and abnormal bleeding patterns.

As suggested by the acronym, the PALM-COEIN classification system includes nine categories: polyp, adenomyosis, 
leiomyoma, malignancy and hyperplasia, coagulopathy, ovulatory disorders, endometrium, iatrogenic and not yet classified [13]. The categories indicated by the PALM acronym can be measured visually because they present structural abnormalities evaluated with clinical examination, imaging techniques or histopathology. Conditions classified in the COEIN group cannot be defined by imaging or histopathology. This classification system has the additional advantage of being usable at the primary care as well as specialist level. It is important to keep in mind that many of these causes of AUB can be asymptomatic, and that AUB itself might be the first symptom.

\section{Polyps}

Polyps are categorized as either absent or present and are diagnosed by ultrasound, hysteroscopy or both, preferably in combination with histopathology. Sub-classification might be developed based on the dimensions, location, number, morphology and histology of the polyps.

\section{Adenomyosis}

Although the relationship between adenomyosis and AUB is unclear, some reports link adenomyosis to AUB [14]. Diagnosis is made by ultrasound, magnetic resonance imaging or histopathology, typically after hysterectomy.

\section{Leiomyomas}

Leiomyomas are classified by size, location (submucosal, intramural, subserosal or combination) and the number of lesions. In many cases, they are asymptomatic; however, in other cases, the first symptom is AUB.

\section{Malignancy and premalignant conditions}

Atypical hyperplasia and cancer are major causes of AUB and, importantly, can occur not only in the postmenopausal period but also during a woman's reproductive years. When a woman with AUB is diagnosed with a premalignant or malignant process, she should be classified according to the appropriate World Health Organisation or FIGO system.

\section{Coagulopathy (systemic disorders of haemostasis)}

This category includes the systemic disorders of haemostasis that are linked to AUB. Although a common cause in this category can be von Willebrand disease, other coagulopathies can also contribute to AUB. It is important to take these conditions into account because, generally, gynaecologists are not familiar with haemostasis diseases. It is also important to consider whether women are medicated with anticoagulants.

\section{Ovulatory disorders}

Women with ovulatory disorders typically present with AUB, which includes both unpredictable bleeding and abnormal flow. However, some women can present with amenorrhoea, light and infrequent bleeding, and HMB (sometimes unpredictable), which needs medical intervention and, in some cases, emergency treatment. The aetiology could be polycystic ovarian syndrome, hypothyroidism, hyperprolactinemia, mental stress, obesity, post-bariatric surgery, post-solid organ transplantation, anorexia or extreme exercise.

\section{Endometrial causes}

If a woman presenting with AUB has cyclical ovulatory cycles and no other obvious cause for the bleeding disturbance, one should consider that the cause might be the endometrium. Most causes are associated with a deficiency in the local production of vasoconstrictors, including endothelin-1 and prostaglandin F2a, or the excessive production of plasminogen activator $[15,16]$. However, clinicians do not have access to many diagnostic tests for these conditions.

\section{latrogenic}

For this classification, it is necessary to take into account the use of intrauterine contraceptives (copper- or levonorgestrel-releasing); gonadal steroids, such as hormonal contraceptive agents; anticonvulsants and antibiotics (rifampicin, griseofulvin); tricyclic antidepressants (amitriptyline, nortriptyline) and phenothiazines; and anticoagulant drugs, such as warfarin, heparin and low-molecular-weight heparin.

\section{Not classified}

Other important causes of AUB are included in this group, such as chronic endometritis, arteriovenous malformations and myometrial hypertrophy.

\section{Treatments}

HMB is a common problem that has significant effects on women's lives and can burden both patients and healthcare systems [17]. HMB accounts for $18.5 \%$ of gynaecologist office visits in the US and $20 \%$ in the UK [18]. More than $5 \%$ of UK women aged 30-49 consult family physicians about this problem each year [18]. In most cases, no pathology is found in women who present with HMB. In women with no endometrial, uterine or endocrine abnormal cause, HMB remains poorly understood, posing a major challenge to developing novel, efficient nonsurgical therapies for HMB.

As stated before, AUB describes a range of menstrual bleeding symptoms, of which the most common and important is HMB. The estimated worldwide prevalence of subjective, self-defined AUB varies greatly, from 4 to $52 \%$ [19]. Women with abnormal bleeding have a lower quality of life than the general female population. There 
are considerable discrepancies between objective measures and women's perceptions of menstrual blood loss [20]. It is agreed that a normal bleeding episode results in menstrual blood loss of 30-40 ml [21], with an upper limit of $80 \mathrm{ml} \mathrm{[6].} \mathrm{However,} \mathrm{blood} \mathrm{loss} \mathrm{reported} \mathrm{by}$ women presenting is often less than $80 \mathrm{ml}$ [22], indicating that patient distress is an important consideration.

The ultimate goal of any form of treatment is to reduce menstrual flow in order to improve quality of life. Pharmaceutical therapies have always been considered the first-line treatment for women complaining of excessive menstrual loss. Conservative and uterine-preserving treatment options are clearly preferred. Surgical treatment tends to follow failed or ineffective medical treatment [23].

\section{Combined oral contraceptive with $E_{2}$ valerate and dienogest}

To improve the unacceptable cycle control observed in clinical studies of ethynil-estradiol $\left(\mathrm{EE}_{2}\right)$-containing combined oral contraceptives (COCs), a new COC was developed, which combines estradiol valerate $\left(\mathrm{E}_{2} \mathrm{~V}\right)$ with the progestin dienogest (DNG), using a dynamic dosing regimen with an oestrogen step-down and a progestin step-up. A double-blind, placebo-controlled study showed that, in comparison to a placebo, oral $E_{2} V / D N G$ is a highly effective, well-tolerated treatment for women with $\mathrm{HMB}$, prolonged menstrual bleeding or heavy and prolonged menstrual bleeding without organic pathology. In the trial, E2V/DNG recipients showed a rapid, large, sustained decrease in menstrual blood loss volume [24]. A multicentre, double-blind, randomized study found that a COC with $E_{2} V / D N G$ was associated with an acceptable bleeding profile, comparable to that of an $\mathrm{EE}_{2}$-containing $\mathrm{COC}[25]$.

$\mathrm{E}_{2} \mathrm{~V} / \mathrm{DNG}$ COC provides an important treatment option which is reversible and also provides contraception for these women [26]. Women with HMB treated with this COC can expect a significant reduction in bleeding. The women who received $\mathrm{E}_{2} \mathrm{~V} / \mathrm{DNG}$ pills reported significantly fewer bleeding/spotting days when compared to those who received EE/LNG $[17.3 \pm 10.4$ vs. $21.5 \pm 8.6$, respectively, $P<0.0001$, reference period 1 (days 1-90) and $13.4 \pm 9 v$ s. $15.9 \pm 7.1$, respectively, $P<0.0001$, reference period 2 (days 91-180)]. This pattern was also observed through cycles 1-7, the occurrence of scheduled withdrawal bleeding per cycle was 77.7-83.2\% with E2V/DNG and 89.5-93.8\% with EE/LNG pills ( $P<0.0001$ per cycle). This therapy also showed few adverse events [27]. Thus, the use of a dynamic dosing regimen, which incorporates different (stepped-down) doses of $\mathrm{E}_{2} \mathrm{~V}$ administered alone or in combination with different (stepped-up) doses of DNG, has resulted in an $E_{2}$-containing
COC a bleeding profile superior to that of other $\mathrm{EE}_{2}$-containing COCs.

\section{Levonorgestrel-releasing intrauterine system}

The levonorgestrel-releasing intrauterine system (LNGIUS, Mirena ${ }^{\circledR}$ ) was developed as a contraceptive device and initially licensed for contraceptive use in the UK in 1995 for three years, extended to five years in 1998 [28]. It became available in the US in 2009. The device contains $20 \mu \mathrm{g}$ of LNG and the steroid is released in a controlled dose over 24 hours for up to 5 years. The effects of the LNG-IUS are mostly local and prevent endometrial proliferation, and some women also have suppression of ovulation. Although developed as a contraceptive, LNG-IUS also reduces menstrual blood loss [29].

The LNG-IUS cannot be used by women with abnormal uterine cavities because the risk of expulsion is unacceptably high [30]. Two recent reviews showed a 71 to $96 \%$ reduction in menstrual blood flow and 20 to $30 \%$ amenorrhoea during the LNG-IUS use [31,32]. In a review, it was shown that the menstrual blood loss reductions reported in the randomized clinical trials were between 71 and $96 \%[32,33]$.

In a recently published, multicentre, randomized trial [34] comparing LNG-IUS with common medical treatments for women with menorrhagia, LNG-IUS and the common medical treatments reduced HMB's adverse effects. The study allocated at random 571 women with menorrhagia to treatment with the LNG-IUS or medical treatment (tranexamic acid, mefenamic acid, combined estrogenprogestogen, or progesterone alone). The Menorrhagia Multi-Attribute Scale (MMAS) was the patient-reported score outcome (ranging from 0 to 100), assessed over a 2-year period. MMAS scores improved from baseline to 6 months in both the LNG-IUS group and the medical treatment group (mean increase, 32.7 and 21.4 points, respectively; $P<0.001$ for both comparisons). The improvement was significantly greater in the LNG-IUS group than in the medical treatment group (mean between-group difference, 13.4 points; 95\% confidence interval [CI], 9.9 to $16.9 ; P<0.001)$. Additionally, LNG-IUS was more effective at reducing the negative effects on quality of life, including work, social and family life and psychological and physical well-being, although no significant between-group difference was observed regarding the domain of mental health.

\section{Tranexamic acid}

Tranexamic acid is a plasminogen activator inhibitor that is able to control HMB by inhibiting the dissolution of thrombosis. Oral tranexamic acid has been associated with reduced menstrual blood loss volume. However, it is 
not a contraceptive, cannot regulate the menstrual cycle, and could be used in women with uterine fibroids $[35,36]$.

A recent study with a new oral formulation of tranexamic acid in women with cyclic HMB showed that during treatment tranexamic acid was well tolerated with a good safety profile and may be used as a therapy for HMB [37]. Furthermore, it was reported [38] that a reduction in HMB was observed during therapy with tranexamic acid when compared with placebo. In two trials, tranexamic acid produced a significant reduction in mean blood loss (-94.0, 95\% CI, -151.4 to $-36.5 ;$ P:0.001) and a significant change in mean reduction of blood loss $(-110.2,95 \% \mathrm{CI}$, -146.5 to -73.8$)$ compared with placebo. However, this improvement was not accompanied by a perceived improvement in monthly menstrual blood loss by the women [35,38].

Other researchers assessed the use of tranexamic acid on HMB. They observed a reduction in menstrual blood loss of 46.7\% (95\% CI, 47.9-51.6\%) with tranexamic acid [39] and others showed that oral tranexamic acid, 2.0 to $4.5 \mathrm{~g}$ daily, for 4 to 7 days per cycle reduced blood loss by $34-59 \%$ [6]. However, comparing the LNG-IUS to tranexamic acid and other conventional medical therapies, a significantly large decrease in the number of bleeding days (mean, 4.0) in the LNG-IUS group compared with other therapies (mean, 2.8 days) was observed. Furthermore, the mean reduction in the number of spotting days was 0.3 days and 1.4 days, respectively [40].

\section{Nonsteroidal anti-inflammatory drugs (such as mefenamic acid)}

NSAIDs are a proposed therapy in ovulatory HMB $[41,42]$ because their use reduces menstrual loss. NSAIDs (e.g. mefenamic acid) approved for the treatment of HMB might also alleviate dysmenorrhoea, but they have a limited effect on the reduction of HMB [42]. When comparing LNG-IUS and mefenamic acid, after six cycles the median menstrual blood loss was $5 \mathrm{ml}$ in the LNG-IUS group and $100 \mathrm{ml}$ in the mefenamic acid group $(P<0.001)$. The median pictorial blood loss assessment chart (PBAC) score was 159 in the mefenamic acid group and 25 in the LNG-IUS group [41]. Furthermore, the use of mefenamic acid in women with AUB induced by etonorgestrelreleasing implant showed that four weeks after initial treatment, a bleeding free-interval of $>20$ days was found in $56.5 \%$ and $21.7 \%$ of the women treated with mefenamic acid or placebo, respectively [42]. The UK National Institute for Health and Clinical Excellence presented information about the use of NSAIDs in the management of HMB and stated that it was associated with a $20-40 \%$ reduction in blood loss. Although the use of mefenamic acid showed a reduction in menstrual flow of $29 \%$, naproxen and ibuprofen also showed a reduction of blood loss of $26 \%$ and $16 \%$, respectively [42].

\section{Conclusions}

Discarding many terms related to menstrual disturbances, including dysfunctional uterine bleeding, would greatly benefit clinicians and researchers. As shown by this review, women with AUB can have one or multiple potential causes of abnormal bleeding, and the accuracy of their diagnosis might depend on the degree of sophistication of the facility at which they seek consultation. The PALM-COEIN system allows clinicians and researchers to identify and classify women with abnormal bleeding and provides reliable information on classification and for comparisons in research settings. The PALM-COEIN classification system is practical and offers the healthcare professional accurate diagnoses and adequate treatment according to the aetiology. For this reason we strongly recommend adoption of this classification for AUB and HMB. Furthermore, possible medical treatments include the use of the LNG-IUS, the use of a novel COC with $\mathrm{E}_{2} \mathrm{~V}$ and DNG, NSAIDs and tranexamic acid.

\section{Abbreviations}

AUB, abnormal uterine bleeding; COC, combined oral contraceptive; DNG, dienogest; DUB, dysfunctional uterine bleeding; $\mathrm{E}_{2} \mathrm{~V}$, estradiol valerate; $\mathrm{EE}_{2}$, ethynil-estradiol; FIGO, International Federation of Gynaecology and Obstetrics; HMB, heavy menstrual bleeding; ICD, International Statistical Classification of Diseases and Health Related Problems; LNG-IUS, levonorgestrel-releasing intrauterine system; MMAS, Menorrhagia Multi-Attribute Scale; NSAIDs, nonsteroidal anti-inflammatory drugs.

\section{Disclosures}

The authors declare that they have no disclosures.

\section{Disclaimer}

This report contains the collective views of two international experts, and does not necessarily represent the decisions or the stated policy of the World Health Organisation.

\section{References}

I. Woolcock JG, Critchley HO, Munro MG, Broder MS, Fraser IS: Review of the confusion in current and historical terminology and definitions for disturbances of menstrual bleeding. Fertil Steril 2008, 90:2269-80.

2. Fraser IS, Parke S, Mellinger U, Machlitt A, Serrani M, Jensen J: Effective treatment of heavy and/or prolonged menstrual bleeding without organic cause: pooled analysis of two multinational, randomised, double-blind, placebo-controlled trials of oestradiol valerate and dienogest. Eur J Contracept Reprod Health Care 2011, 16:258-69.

FlOOOPrime

RECOMMENDED 
3. Liu Z, Doan QV, Blumenthal P, Dubois RW: A systematic review evaluating health-related quality of life, work impairment, and health-care costs and utilization in abnormal uterine bleeding. Value Health 2007, 10:183-94.

\section{FIOOOPrime}

4. Hallberg L, Högdahl AM, Nilsson L, Rybo G: Menstrual blood loss-a population study. Variation at different ages and attempts to define normality. Acta Obstet Gynecol Scand 1966, 45:320-5I.

5. Kaunitz AM, Bissonnette F, Monteiro I, Lukkari-Lax E, Muysers C, Jensen JT: Levonorgestrel-releasing intrauterine system or medroxyprogesterone for heavy menstrual bleeding: a randomized controlled trial. Obstet Gynecol 2010, I 16:625-32.

\section{FlOOOPrime}

6. CG44 Heavy menstrual bleeding: NICE guideline. 2007.

7. Munro MG, Heikinheimo O, Haththotuwa R, Tank JD, Fraser IS: The need for investigations to elucidate causes and effects of abnormal uterine bleeding. Semin Reprod Med 20II, 29:4I0-22.

\section{FlOOOPrime}

8. Fraser IS, Critchley HOD, Broder M, Munro MG: The FIGO recommendations on terminologies and definitions for normal and abnormal uterine bleeding. Semin Reprod Med 20I I, 29:383-90.

9. Munro MG, Critchley HOD, Fraser IS: The flexible FIGO classification concept for underlying causes of abnormal uterine bleeding. Semin Reprod Med 20II, 29:39I-9.

\section{FlOOOPrime RECOMMENDED}

10. Dueholm M: Levonorgestrel-IUD should be offered before hysterectomy for abnormal uterine bleeding without uterine structural abnormalities: there are no more excuses! Acta Obstet Gynecol Scand 2009, 88: I 302-4.

II. Fraser IS, Critchley HOD, Munro MG, Broder M: Can we achieve international agreement on terminologies and definitions used to describe abnormalities of menstrual bleeding? Hum Reprod 2007, 22:635-43.

12. International Classification of Disease (ICD): International Statistical Classification of Diseases and Related Health Problems. $10^{\text {th }}$ Revision: Volume 2. World Heath Organisation (WHO); 2010. [www.who.int/classifications/icd/ICD IOVolume2_en_2010.pdf]

13. Munro MG, Broder M, Critchley HOD, Matteson K, Haththotuwa R, Fraser IS: An international response to questions about terminologies, investigation, and management of abnormal uterine bleeding: use of an electronic audience response system. Semin Reprod Med 20I I, 29:436-45.

14. Rizvi G, Pandey H, Pant H, Chufal SS, Pant P: Histopathological correlation of adenomyosis and leiomyoma in hysterectomy specimens as the cause of abnormal uterine bleeding in women in different age groups in the Kumaon region: A retroprospective study. J Midlife Health 20I3, 4:27-30.

\section{FlOOOPrime}

RECOMMENDED

15. Gleeson NC: Cyclic changes in endometrial tissue plasminogen activator and plasminogen activator inhibitor type $I$ in women with normal menstruation and essential menorrhagia. Am J Obstet Gynecol 1994, I 7 I: I 78-83.

16. Smith SK, Abel MH, Kelly RW, Baird DT: A role for prostacyclin (PGi2) in excessive menstrual bleeding. Lancet 198I, 1:522-4.

17. Nicholson WK, Ellison SA, Grason H, Powe NR: Patterns of ambulatory care use for gynecologic conditions: a national study. Am J Obstet Gynecol 200 I, 184:523-30.

\section{FlOOOPrime RECOMMENDED}

18. Coulter A, Bradlow J, Agass M: Outcomes of referrals to gynecology outpatient clinics for menstrual problems: an audit of general practice records. Br J Obstet Gynaecol I99I, 98: 789-96.

19. McCormick A, Fleming D, Charlton J: Morbidity statistics from general practice: fourth national morbidity study 199I-1992. HMSO 1995 .

20. Fraser IS, Langham S, Uhl-Hochgraeber K: Health-related quality of life and economic burden of abnormal uterine bleeding. Exp Rev Obstet Gynecol 2009, 4:179-89.

21. Warner P, Critchley HO, Lumsden MA, Campbell-Brown M, Douglas A, Murray G: Referral for menstrual problems: cross sectional survey of symptoms, reasons for referral, and management. BMJ 200I, 323:24-8.

22. Hale GE, Manconi F, Luscombe G, Fraser IS: Quantitative measurements of menstrual blood loss in ovulatory and anovulatory cycles in middle- and late-reproductive age and the menopausal transition. Obstet Gynecol 2010, I I 5:249-56.

\section{FlOOOPRime
RECOMMENDED}

23. Chimbira $\mathrm{TH}$, Anderson $\mathrm{AB}$, Turnbull $\mathrm{AC}$ : Relation between measured menstrual blood loss and patient's subjective measurement of loss, duration of bleeding, number of sanitary towels used, uterine weight and endometrial surface area. $\mathrm{Br}$ J Obstet Gynaecol 1980, 87:603-9.

24. Beebeejaun $Y$, Varma R: Heavy menstrual flow: current and future trends in management. Rev Obstet Gynecol 20I3, 6: I55-64.

25. Jensen JT, Parke S, Mellinger U, Machlitt A, Fraser IS: Effective treatment of heavy menstrual bleeding with estradiol valerate and dienogest: a randomized controlled trial. Obstet Gynecol 2011, II 7:777-87.

\section{FIOOOPrime
RECOMMENDED}

26. Ahrendt HJ, Makalová D, Parke S, Mellinger U, Mansour D: Bleeding pattern and cycle control with an estradiol-based oral contraceptive: a seven-cycle, randomized comparative trial of estradiol valerate/dienogest and ethinyl estradiol/levonorgestrel. Contraception 2009, 80:436-44.

\section{FlOOOPrime
RECOMMENDED}

27. Palacios S, Wildt L, Parke S, Machlitt A, Romer T, Bitzer J: Efficacy and safety of a novel oral contraceptive based on oestradiol (oestradiol valerate/dienogest): a Phase III trial. Eur J Obstet Gynecol Reprod Biol 2010, 149:57-62.

\section{FlOOOPrime}

28. Micks EA, Jensen JT: Treatment of heavy menstrual bleeding with the estradiol valerate and dienogest oral contraceptive pill. Adv Ther 2013, 30:1-13.

29. Harrison-Woolrych M, Raine JM: Levonorgestrel intrauterine device can be left in place for five years. BMJ 1998, 317:149.

30. Endrikat J, Vilos G, Muysers C, Fortier M, Solomayer E, LukkariLax E: The levonorgestrel-releasing intrauterine system provides a reliable, long-term treatment option for women with idiopathic menorrhagia. Arch Gynecol Obstet 2012, 285: || $17-2 \mid$.

FlOOOPrime RECOMMENDED

3I. Lethaby AE, Cooke I, Rees M: Progesterone/progestogen releasing intrauterine systems for heavy menstrual bleeding. Cochrane Database Syst Rev 2000, 2:CD002 I 26.

\section{FlOOOPrime
RECOMMENDED}

32. Stewart A, Cummins C, Gold L, Jordan R, Phillips W: The effectiveness of the levonorgestrel-releasing intrauterine system in menorrhagia: a systematic review. BJOG 200I, 108:74-86.

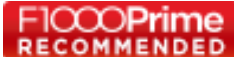


33. Samuel NC, Clark T): Future research into abnormal uterine bleeding. Best Pract Res Clin Obstet Gynaecol 2007, 21:1023-40.

34. Gupta J, Kai J, Middleton L, Pattison H, Gray R, Daniels J; ECLIPSE Trial Collaborative Group: Levonorgestrel intrauterine system versus medical therapy for menorrhagia. N Engl J Med 2013, 368: $128-37$

\section{FlOOOPrime} RECOMMENDE

35. Wellington K, Wagstaff AJ: Tranexamic acid: a review of its use in the management of menorrhagia. Drugs 2003, 63 1417-33.

36. Eder S, Baker J, Gersten J, Mabey RG, Adomako TL: Efficacy and safety of oral tranexamic acid in women with heavy menstrual bleeding and fibroids. Womens Health (Lond Engl) 2013, 9:397-403.

\section{FlOOOPrime}

\section{RECOMMENDED}

37. Lukes AS, Freeman EW, Van Drie D, Baker J, Adomako TL: Safety of tranexamic acid in women with heavy menstrual bleeding: an open- label extension study. Womens Health (Lond Engl) 2011, 7:591-8.

FlOOOPrime
38. Lethaby A, Farquhar C, Cooke I: Antifibrinolytics for heavy menstrual bleeding. Cochrane Database Syst Rev 2000, 4:CD000249.

FlOOOPrime

39. Coulter A, Kelland J, Peto V, Rees MC: Treating menorrhagia in primary care: an overview of drug trials and a survey of prescribing practice. Int J Technol AssessHealth Care 1995, I I:456-47I.

40. Lee BS, Ling X, Asif S, Kraemer P, Hanisch JU, Inki P: Levonorgestrel-releasing intrauterine system versus conventional medical therapy for heavy menstrual bleeding in the Asia-Pacific region. Int J Gynaecol Obstet 2013, I 21:24-30.

4I. Reid PC, Virtanen-Kari S: Randomised comparative trial of the levonorgestrel intrauterine system and mefenamic acid for the treatment of idiopathic menorrhagia: a multiple analysis using total menstrual fluid loss, menstrual blood loss and pictorial blood loss assessment charts. BJOG 2005, I | 2: | | 2 |-5.

FlOOOPrime

PEOMMENDED

42. Phaliwong P, Taneepanichskul S: The effect of mefenamic acid on controlling irregular uterine bleeding second to Implanon use. J Med Assoc Thai 2004, 87(Suppl 3):S64-8.

\section{FlOOOPrime}

